\title{
Molecular genetic studies on ASYMMETRIC LEAVES2 (AS2) of Arabidopsis: Insight into the function of the AS2 protein
}

\author{
Yoshihisa Ueno $^{1}$, Patricia Springer ${ }^{2}$ \\ 1 Division of biological sciences, Graduate school of sciences, Nagoya University, \\ Furo-cho, Chikusa-ku, Nagoya 464-8602 Japan \\ 2 Department of Botany and Plant Sciences, Center for Plant Cell Biology, University of California, \\ Riverside, CA 92521, USA
}

\begin{abstract}
Summary: The ASYMMETRIC LEAVES2 (AS2) gene is involved in leaf development along adaxial-abaxial, mediallateral and proximal-distal axes in Arabidopsis. The AS2 gene belongs to the AS2/LATERAL ORGAN BOUNDARIES $(L O B)$ family. There are 42 members of the $A S 2 / L O B$ family in the Arabidopsis genome. Many recent studies revealed that $A S 2 / L O B$ family genes are involved in various physiological processes including the regulation of development and metabolism in plants. The approximately 100 amino acid AS2/LOB-domain, which defines this family, is highly conserved. Conserved regions include the C-motif, an internal region containing an invariant glycine residue, and a leucine-zipper-like motif, in the case of class I proteins. The conserved AS2/LOB-domain of AS2 cannot be functionally replaced by those of other members of the family. AS2 acts in a same pathway as that of AS1, which is an ortholog of ROUGH SHEATH2 of maize and PHANTASTICA of snapdragon. Recent molecular genetic studies for the role of AS2 provided important information. The regulation of gene expression and leaf development by AS2 is genetically linked with the regulations based on chromatin level, post-transcriptional level, protein metabolism and cell proliferation. These novel insights contribute to a better understanding of the role of $A S 2 / L O B$ family genes for plant morphogenesis and physiological responses.
\end{abstract}

Key words: ASYMMETRIC LEAVES2 (AS2), LOB, Arabidopsis, leaf development, AS2/LOB-domain

\section{AS2/LOB family}

The ASYMMETRIC LEAVES2 (AS2) gene was isolated as a gene involved in the formation of leaf shape and venation pattern in Arabidopsis (Rédei and Hirono 1964, Semiarti et al. 2001, Iwakawa et al. 2002). The LATERAL ORGAN BOUNDARIES (LOB) gene was isolated as a gene whose transcripts were enriched in the boundary region between the shoot apical meristem
(SAM) and leaf primordia of Arabidopsis (Shuai et al. 2002). AS2 and LOB share a common domain that is conserved in proteins throughout the plant kingdom, namely the AS2/LOB-domain (Fig. 1). This domain is found in the N-terminal halves of the AS2 and LOB proteins (Iwakawa et al. 2002, Shuai et al. 2002). There are 42 genes encoding AS2/LOB-domain containing proteins in the Arabidopsis genome; these genes are

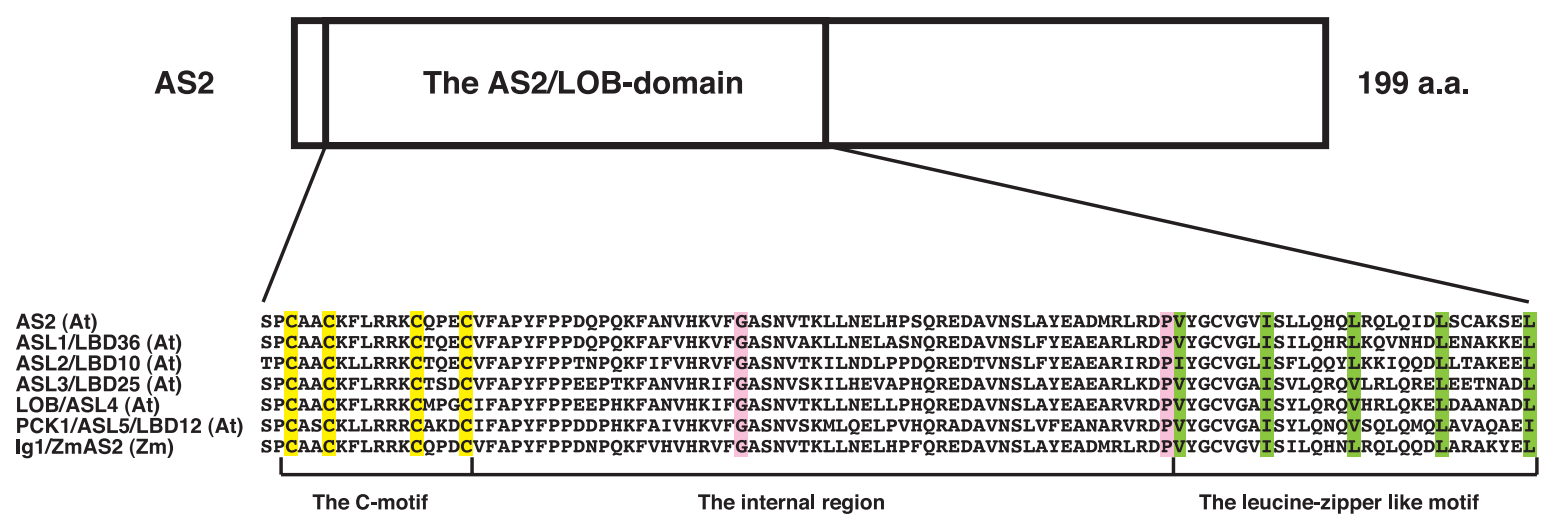

Figure 1 Structure of AS2 and the AS2/LOB-domain. Four Cys residues composing the C-motif are shaded by yellow. The conserved Gly and Pro residues are shaded by pink. The hydrophobic residues composing the leucine-zipper like motif are shaded by green. PCK1: Peacock1 (Nakazawa et al. 2003). At: Arabidopsis. Zm: maize. 
classified as belonging to a gene family named as AS2/ $L O B$ family. The 41 members other than $A S 2$ were named as $A S 2-L I K E 1$ to 41 (ASL1-41). Alternatively the 41 members other than $\angle O B$ were named as $L O B$ DOMAIN1-33 (LBD1-33) and LBD35-42. Here LBD34 is not included in the family, as it might be a pseudogene because the conserved glycine (Gly) residue described below is not found in the predicted amino acid sequence. In rice, 35 genes belonging to the $A S 2 / L O B$ family have been reported (Yang et al. 2006). Among 42 members of the Arabidopsis AS2/LOB family genes, 36 members ( $A S 2$ and ASL1-35) are categorized as class I and 6 members (ASL36-42) as class II, on the basis of the amino acid sequences of their AS2/LOB-domains.

Many recent studies revealed that $A S 2 / L O B$ family genes are involved in various physiological events including the regulation of development and metabolism in plants. ASL1/LBD36 has a partially redundant function with $A S 2$ to repress class $1-K N O X$ expression in flower development (Chalfun-Junior et al. 2005). ASL3/LBD25 is involved in auxin-responses and photomorphogenesis (Mangeon et al. 2011). ASL9/LBD3 appears to regulate cytokinin-dependent development (Naito et al. 2007). ASL16/LBD29, ASL18/LBD16 and ASL20/LBD18 are auxin-regulated and required for lateral root initiation (Okushima et al. 2007). ASL19/LBD30 and ASL20/ $L B D 18$ act as positive regulators of xylem development (Soyano et al. 2008). ASL19/LBD30 is also required for proper cell division in embryogenesis and for the development of cotyledons (Borghi et al. 2007). ASL29/ $L B D 27$ is essential for the asymmetric division and the consequent development of the male gametophyte (Oh et al. 2010). ASL39/LBD37, ASL40/LBD38 and $A S L 41 / L B D 39$ regulate the expression of anthocyanin biosynthesis genes depending on the nutrient (Rubin et al. 2009, Albinsky et al. 2010). In maize, loss-of-function mutations in genes that encode proteins with an AS2/ LOB domain, namely, indeterminate gametophytel (igl) and ramosa2 (ra2), affect the development of the embyo sac and inflorescence branching patterns, respectively (Bortiri et al. 2006, Evans 2007). The Crown rootless1/Adventitous rootless 1 (Crll/Arll) gene of rice, and the rootless concerning crown and seminal roots (rtcs) gene of maize encode proteins with AS2/LOB domains that exhibit high degrees of identity, in terms of their respective amino acid sequences, with those of ASL16/LBD29 and ASL18/LBD16 of Arabidopsis (Inukai et al. 2005, Liu et al. 2005, Taramino et al. 2007). The common involvement in auxin responses and lateral root formation indicate functional conservation between the Arabidopsis, rice, and maize proteins.

\section{AS2/LOB-domain}

Because $A S 2 / L O B$ family genes are involved in various aspects of plant developmental and physiological responses, biochemical characterization of the AS2/LOBdomain is important to develop a better understanding of the nature of plant development and physiological responses. The $\mathrm{Cx}_{2} \mathrm{Cx}_{6} \mathrm{Cx}_{3} \mathrm{C}$ sequence ( $\mathrm{C}$ : cysteine; $\mathrm{x}$ : unconserved; positions from 10 to 24 in AS2) is completely conserved in the $\mathrm{N}$-terminal region of the AS2/LOB-domain of all the predicted proteins belonging to the AS2/LOB family of Arabidopsis (Fig. 1). The sequence was named the C-motif. A leucine-zipper like sequence is conserved in the C-terminal region of AS2/ LOB-domain belonging to class I AS2/LOB family. Class II AS2/LOB-domain proteins appear to lack the functional leucine-zipper motif. The amino acid sequence of the internal region between the $\mathrm{C}$-motif and the leucine-zipper like motif is also conserved. Especially, the Gly and Pro residues at positions 46 and 80, respectively, in AS2 are conserved through all members of AS2/LOB family in Arabidopsis (Iwakawa et al. 2002, Shuai et al. 2002). In the amino acid sequence of the mutant AS2 protein encoded by the as 2-5 mutant allele, the conserved Gly is replaced by a Glu residue, suggesting that the conserved Gly residue has an essential role (Semiarti et al. 2001, Iwakawa et al. 2002).

The amino acid sequence of the $\mathrm{C}$-terminal region of each AS2/LOB family protein is variable and might confer functional specificity to each protein. Indeed, the mutant AS2 protein encoded by the as 2-4 mutant allele is truncated so that it lacks a complete $\mathrm{C}$-terminus and its full function. However, the conserved AS2/LOB-domain 
also confers a specific function to the AS2 protein, as the AS2/LOB-domain of AS2 cannot be functionally replaced by those of other members of the family (Matsumura et al. 2009). This result suggests that the conserved AS2/LOBdomain of each member of the AS2/LOB family plays a role in specifying the function of each protein. Similarly, the C-terminus of LOB/ASL4 functions to stabilize or enhance protein-protein interactions rather than to specify the interaction in vitro (Husbands et al. 2007).

The recombinant LOB/ASL4, AS2, ASL6/LBD4, ASL9/LBD3, ASL18/LBD16 and ASL38/LBD41 proteins, members of phylogenetically distinct groups within the family that are functionally diverse, are capable of binding DNA with the consensus sequence of 5'-GCGGCG-3' in vitro (Husbands et al. 2007). These data indicate that AS2/LOB proteins have the same or similar DNA-binding activity, suggesting that recognition of DNA sequence is not sufficient to confer functional specificity to each member of AS2/LOB family. One example is the specific partner for proteinprotein interactions. In the case of LOB/ASL4, the AS2/ LOB-domain mediates not only DNA-binding but also homodimerization and the interaction with another protein, bHLH048.

\section{Protein-protein interaction between AS1 and AS2}

The phenotype of asymmetric leaves1 (asl) mutants resembles that of as 2 mutants (Rédei, 1965, Semiarti et al. 2001). The AS1 gene encodes the MYB-domain containing protein, which is an ortholog of ROUGH SHEATH2 (RS2) of maize and PHANTASTICA (PHAN) of snapdragon (Byrne et al. 2000, Timmermans et al. 1999, Tsiantis et al. 1999, Waites et al. 1998). Green fluorescent protein (GFP)-fused RS2 (RS2-GFP) or PHAN (PHAN-GFP) can functionally replace AS1 and restore the phenotype of asl mutants, suggesting that RS2 and PHAN are evolutionally conserved functional orthologs of AS1 (Theodoris et al. 2003, Nurmberg et al. 2007). The as 1 mutation does not enhance the phenotype of as 2 mutants and vice versa (Serrano-Cartagena et al. 1999). Thus, AS1 and AS2 act in a same pathway. When AS1 and AS2 were co-expressed in a single cell, both proteins were co-localized as speckled bodies (AS2-bodies) adjacent to nucleoli (Ueno et al. 2007). Recombinant AS1 and AS2 proteins can interact in vitro (Xu et al. 2003). Based on these results, it is believed that $\mathrm{AS} 1$ and AS2 proteins function in a heteromeric protein complex. However, the evidence of their interaction in vivo has not yet been shown. The accumulation pattern of transcripts of $A S 1$ is not same as that of $A S 2$ (Iwakawa et al. 2007). In addition, an $A S 2$-independent function of AS1 was reported. AS1 directly represses transcription of jasmonic acid (JA)-responsive genes and regulates the plant immune response, an activity that does not depend on the endogenous $A S 2$ gene (Nurmberg et al. 2007). It remains elusive whether the interaction between AS1 and AS2 proteins is essential for the developmental roles of both proteins.

\section{Transcriptional regulation by AS1 and AS2}

Leaves develop along three axes - proximal-distal, adaxial-abaxial and medial-lateral. Starting as a bulge on the flank of the SAM, the newly initiated leaf becomes asymmetric. The meristem provides leaves with an inherent sidedness, with the adaxial side adjacent to the meristem and the proximal end attached to the meristem (Fig. 2). Polarization along these axes eventually leads to the asymmetric distribution of cell types in the mature leaf that is critical for the physiology of the plant. For

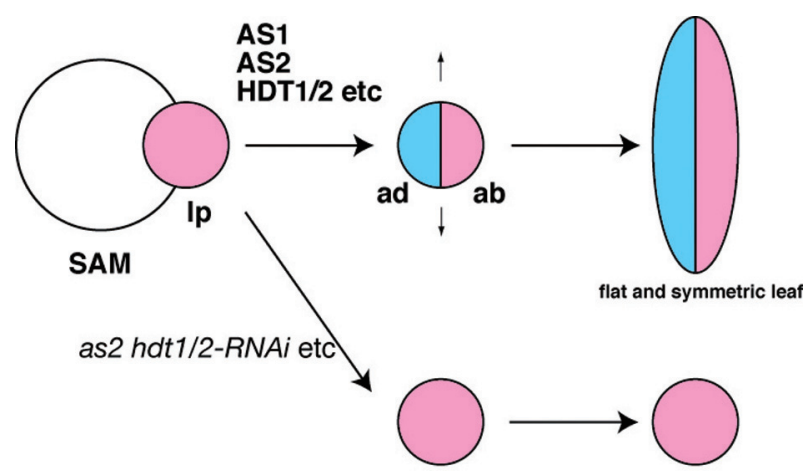

Figure 2 Establishment of adaxial-abaxial polarity in a developing leaf. The leaf newly initiated from the SAM is initially radial, and lacks characteristics of adaxial domain when it is incipient primordium. Adaxial identity is obtained during development. AS2, AS1 and other redundant factors are involved in this step. SAM: shoot apical meristem (large circle). lp: leaf primordium (small circle). ad: adaxial domain. ab: abaxial domain 
example, the adaxial side of the leaf blade often consists of cells specialized for light harvesting while the abaxial side contains cells involved in gas exchange to maximize photosynthesis.

The asl and as 2 mutants are deficient in leaf development along adaxial-abaxial and medial-lateral axes (Semiarti et al. 2002, Xu et al. 2003). Conversely, overexpression of $A S 2$ also affects the adaxial-abaxial polarity of the leaf (Lin et al. 2003). Transcripts of genes related to the abaxial domain, KANADI1 (KAN1), KAN2, ETTIN (ETT)/AUXIN RESPONSE FACTOR3 (ARF3), FILAMENTOUS FLOWER (FIL) and YABBY5 (YAB5) are highly or ectopically accumulated in as 1 or as 2 mutant plants (Garcia et al. 2006, Huang et al. 2006, Iwakawa et al. 2007, Takahashi et al. 2008, Xu et al. 2006).

One of the earliest indications of leaf development is the downregulation at the site of incipient primordia of class1-KNOX genes, which are specifically expressed in the meristem. Through KNOX gene repression, a switch from an indeterminate to a determinate fate occurs in the small group of cells that will be the immediate precursor of the leaf primordium (Moon and Hake 2010). The AS2 protein directly represses the transcription of BREVIPEDICELLUS (BP)/KNAT1 and KNAT2 in the presence of AS1 (Guo et al. 2008). The accumulation of transcripts and activation of promoters of $B P, K N A T 2$ and KNAT6, all belonging to class1-KNOX genes, are ectopically found in leaves of as 1 and as 2 mutants (Ori et al. 2000, Semiarti et al. 2001). However, the ectopic expression of class1-KNOX genes in leaves does not distort leaf initiation, but affects leaf patterning along the proximal-distal axis, in part by altering levels of gibberellin (Ikeazaki et al. 2010, Ramirez et al., 2009, Sakamoto et al. 2001). These findings indicate that ASI and $A S 2$ are also involved in patterning leaf development along the proximal-distal axis. Studies of blade on petiole (bop) of Arabidopsis, a mutant with defects in proximaldistal identity, are consistent with this idea. The bop mutants accumulate class1-KNOX transcripts in the leaf and the BOP complex directly and positively regulates the transcription of AS2 (Ha et al. 2003, Jun et al. 2010).

Although defects in adaxial-abaxial polarity of leaves in as 1 and as 2 mutants were not due to the ectopic expression of class1-KNOX genes (Ikezaki et al. 2010), ectopic class1-KNOX expression is capable of affecting the adaxial-abaxial polarity of floral organs in Arabidopsis. The class1-KNOX genes have the potential to be involved in the establishment of adaxial-abaxial polarity in leaves in another species, tobacco. ARF6 and ARF8, in parallel with AS1 and AS2, repress the class1KNOX genes in Arabidopsis. Ectopic expression of class1-KNOX genes affects the elongation and adaxialabaxial polarity of floral organs through altered JA biosynthesis in arf6 arf8 double mutants (Tabata et al. 2010). NTH15 of tobacco, which is related to SHOOT MERISTEMLESS of Arabidopsis, is predominantly transcribed in the SAM and the adaxial domains of leaf primordia. The antisense repression of NTH15 causes plants deficient in the development of adaxial domains of leaves (Tamaoki et al. 1997). Therefore, it appears that ectopically expressed class $1-K N O X$ genes might be able to affect adaxial-abaxial polarity of leaf-like organs.

In the presence of AS1, a main role for the AS2 protein is the transcriptional repression of several genes including class $1-K N O X$ genes and genes related to leaf polarity, as described above. It is indeed reported that the $\mathrm{C}$-terminal region of the AS1 protein has the activity of transcriptional repression (Guo et al. 2008). It was, however, reported that either the $\mathrm{N}$ - or C-terminal half of maize RS2 protein could partially restore the phenotype of Arabidopsis as1 mutants (Theodoris et al. 2003). In addition, microarray analysis revealed that the transcript level of over 289 genes was possibly upregulated by AS1 and AS2 directly or indirectly (Takahashi et al. 2008). We cannot exclude the possibility that AS2 or the AS1-AS2 complex act as a transcriptional activator. The identification of direct target genes of AS1 and AS2 will be a crucial step to elucidate the biological and biochemical roles of these proteins. Furthermore, considering the results derived from molecular genetic studies (Table 1), we may assume that the mechanism underlying the transcriptional regulation by $\mathrm{AS} 1$ and/or AS2 is novel or that AS1 and/or AS2 also appear(s) to play a role other than in transcriptional regulation. 
Table 1 The mutation that enhance the phenotype of as 1 or as 2 mutants

\begin{tabular}{lll}
\hline Mutant & Gene product or its role & Reference \\
\hline$<$ Gene silencing $>$ & & \\
$r d r 6$ & ta-siRNA pathway & Garcia et al. 2006, Li et al. 2005 \\
sgs3, ago7 & ta-siRNA pathway & Xu et al. 2006 \\
$<$ Protein metablism or cell proliferation $>$ & & \\
$r p l 5, r p l 9, r p l 10 a, r p l 28 a, r p l 24 b$ & ribosomal proteins & Pinon et al. 2008, Yao et al. 2008 \\
pt2a, rpt4a, rpt5a, rpnla, rpn9a, pad1, pbe1 & 26S proteasome & Huang et al. 2006 \\
atate1, 2 & N-end rule & Graciet et al. 2009 \\
ae7 & DUF59 protein & Yuan et al. 2010 \\
an3 & GIF1 & Horiguchi et al. 2010, Wang et al. 2011 \\
$<$ chromatin-related $>$ & & \\
$h i r a(\mathrm{kd})$ & chromatin assembly factor & Phelps-Durr et al. 2005 \\
$p k l$ & chromatin remodeling factor & Ori et al. 2000 \\
$h d t 1,2(\mathrm{kd})$ & HDAC & Ueno et al. 2007 \\
\hline
\end{tabular}

kd: knock-down

\section{Gene silencing pathway}

Gene silencing pathways are complex and partially overlapping, but at least three basic classes can be distinguished: post-transcriptional gene silencing (PTGS) mediated by small interfering RNA (siRNA), silencing mediated by microRNAs, and transcriptional gene silencing (TGS) mediated by siRNA-directed methylation of DNA and histone proteins. MicroRNA- and transacting siRNA- (ta-siRNA-) mediated pathways posttranscriptionally regulate the expression of endogenous genes and consequently plant development. In plants, PTGS is an important antiviral response that suppresses viral gene expression through siRNA-mediated viral RNA degradation. To counteract the host PTGS response, viruses encode various suppressors of RNA silencing.

Recent studies revealed that AS1 and AS2 play roles in RNA silencing pathways. AS1 and AS2 have redundant functions in the ta-siRNA pathway to regulate adaxial-abaxial polarity in leaves (Garcia et al. 2006, $\mathrm{Li}$ et al. 2005, Xu et al. 2006). The accumulation of microRNA165 (miR165) and miR166 (miR165/166), which negatively regulate PHABULOSA (PHB), PHAVOLUTA (PHV), REVOLUTA (REV), CORONA $(C N A)$ and $A T H B 8$, is negatively regulated by AS1 and AS2 (Li et al. 2005, Ueno et al. 2007). Interestingly, the levels of miR165/166 precursors are unaffected by gain- or loss-of-function of AS2 (Ueno et al. 2007). In addition, a viral silencing suppressor, when overproduced in Arabidopsis plants, represses the accumulation of miR165/166. $\beta C 1$, an RNA silencing suppressor encoded by the ORF located on DNA $\beta$ of the Tomato yellow leaf curl China virus (TYLCCNV), interacts with AS1 and partially mimics the function of AS2 including the repression of miR165/166 and leaf morphogenesis (Yang et al. 2008). Because of the biochemical similarities between PTGS and the endogenous miRNA pathway, viral suppressors also interfere with the latter, thereby causing alterations in plant development (Kasschau et al. 2003). Although it has not yet been known whether the regulation is direct or not, AS1 and AS2 might posttranscriptionally regulate the expression of miR165/166.

\section{Protein metabolism and cell proliferation}

Genes encoding the factors involved in protein synthesis or degradation pathways genetically interact with the $A S 1$ and $A S 2$ genes. Mutations in genes encoding several subunits of the ribosome enhance the phenotype of $a s 1$ or as 2 mutant plants (Pinon et al. 2008, Yao et al. 2008). It is, however, not yet known whether the function of ribosome itself is related to that of AS1 and AS2. The genetic interaction between the genes related to ribosomal RNA and as 1 or as 2 would give us important information. 
On the other hand, mutations in genes encoding several subunits of the $26 \mathrm{~S}$ proteasome also enhance the phenotype of as 1 or as 2 mutant plants (Huang et al. 2006). In addition, it was reported that arginyl-tRNAprotein transferases, which are involved in $\mathrm{N}$-terminal amino acid residues-dependent protein degradation, also have a partially redundant function with AS1 (Graciet et al. 2009).

A possible explanation for why mutations disrupting protein synthesis or degradation pathways enhance the phenotype of as 1 and as 2 mutants is that proper cell proliferation is required for leaf polarity establishment.

The as 1/2 enhancer7 (ae7) mutation disrupting the gene encoding DUF59 (domain of unknown function 59) protein enhances the phenotype of as 1 and as 2 mutants (Yuan et al. 2010). Mutation in ANGUSTIFOLIA3 (AN3), which encodes GRF-INTERACTING FACTOR1 (GIF1), also enhances the phenotype of as 1 and as2 mutants (Horiguchi et al. 2010, Wang et al. 2011). The $A E 7$ and $A N 3$ genes are involved in the promotion of cell proliferation. The switch from cell proliferation to differentiation often coincides with the switch from the mitotic cell cycle to the endoreduplication cycle during leaf development (Boudolf et al. 2004, Ishida et al. 2010). The ploidy level is high in the an3 mutants compared to that of wild-type plants (Wang et al. 2011). Proper cell division and consequent polarized cell proliferation might be important for the establishment of leaf polarity. Cell proliferation and the expression of ASI might be partially regulated by a common mechanism. CINCINNATAlike (CIN-like) TCP family proteins are transcription factors involved in cell proliferation and consequent leaf shape formation (Nath et al. 2003, Palatnik et al. 2003). Koyama et al (2010) reported that $\mathrm{TCP} 3$, one of $\mathrm{CIN}$ like TCPs, directly activated the transcription of AS1.

\section{Chromatin related factors}

Factors related to chromatin regulation genetically interact with the $A S 1$ or $A S 2$ genes. A reduction in HIRA function or the loss-of-function pickle $(p k l)$ mutation enhances the phenotype of as 1 and as 2 plants (Ori et al. 2000, Phelps-Durr et al. 2005). The HIRA protein is a chromatin assembly factor that can physically interact with AS1 (Phelps-Durr et al. 2005). The $P K L$ gene encodes a CHD3 ATP-dependent chromatin remodeling factor (Ogas et al. 1999). Mi-2, a mammalian homolog of $\mathrm{PKL}$, is a component of a protein complex that includes histone deacetylases (HDACs, Ahringer 2000), suggesting that some genes for HDACs may also genetically interact with as 1 or as2. Indeed, treatment with inhibitors of HDAC activity enhanced leaf polarity defects in the as 1 and as 2 mutant plants. The responsible genes, HDT1/HD2A and HDT2/HD2B (HDT1/2), were identified by an RNAi-library screening method (Fig. 3). The knock-down of HDTl/2 enhances the phenotype of as 2 mutants (Ueno et al. 2007). HDT1/2 are Arabidopsis homologs of maize HD2 (Dangl et al. 2001), which was originally isolated by biochemical purification from germinated embryos of maize (Lusser et al. 1997). What is the overlapping role among HDT1/2 and AS2? The HDT1/2 pathway may be related to ribosome or cell proliferation. HDT1 is involved in the transcriptional

Cloning of each gene belonging to the family of interest
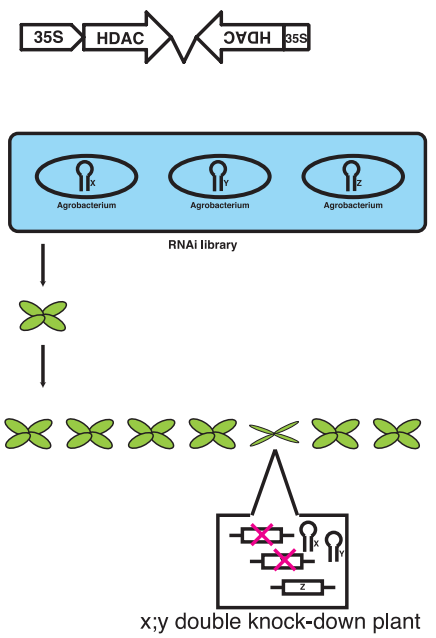

(Genes for HDACs in our case)

$\downarrow$

Construction \& transformation of agrobacterium one by one

$\downarrow$

Mix of agrobacterium culture

$\downarrow$

Transformation of plants by the mixture (the as2-1 mutant Arabidopsis in our case)

$\downarrow$

Screening of $\mathrm{T} 1$ generation (leaf shape in our case)

$\downarrow$

Examination of the introduced T-DNAs

Figure 3 Schematic model for screening of an RNAi-library to functionally characterize individual members of a gene family of interest. 
repression of rDNA genes (Lawrence et al. 2004). The mRNA and activity levels of HD2 are relatively high during germination of maize embryos, in which cell proliferation is vigorous (Georgieva et al. 1991, Lusser et al. 1997). The expression levels of HDT1/2 are high in shoot apices and region in which cell proliferation occurs, and reduced by the an3 mutation (Horiguchi et al. 2010, Wu et al. 2000, Zhou et al. 2004). Alternatively, nuclear structure may possibly be related to the function of HDT1/2 or AS2. The predominant accumulation of HD2, HDT1 and HDT2 proteins is found in nucleoli (Lawrence et al. 2004, Lusser et al. 1997, Zhou et al. 2004). The function of the nucleolus remains largely unknown. It is notable that the predominant accumulation of AS1 and AS2 proteins is observed in AS2-bodies, which are physically near nucleoli, and that not only leaf polarity but also the repression of miR165/166 is affected by the inhibition of HDACs in the as 2 mutant background (Ueno et al. 2007). Investigating such a phenotype might be a clue to dissect the molecular function of HDT1/2 and AS2.

Many recent studies revealed that members of the AS2/LOB family are involved in various aspects of plant growth and development. The biochemical characteristics of the AS2/LOB-domain proteins are of raising importance. The AS2/LOB family proteins act as transcriptional regulators. AS2 is not only one of key regulators in leaf development but also the best model molecule for AS2/LOB family proteins. Again, genetic studies for as 1 and as 2 mutants suggest that the mechanism underlying the transcriptional regulation by AS1 and/or AS2 is novel or that AS1 and/or AS2 may also have additional role besides that of transcriptional regulation.

\section{Acknowledgement}

The research work by YU was done in the lab of Prof Yasunori Machida. The research works in Machida's laboratory was supported in part by a Grant-in-Aid for Scientific Research on Priority Areas and Grants-in-Aid for young scientists (B) (to YU) from the Ministry of
Education, Culture, Sports, Science and Technology of Japan. YU is a recipient of the fellowships from Inamori Foundation and Tokai Sangyou Gijutsu Shinkou Zaidan. Research on AS2/LOB-domain proteins in the Springer lab was supported by the National Science Foundation (IBN-0318822 and IBN-0420202).

\section{References}

Albinsky, D., Kusano, M., Higuchi, M., Hayashi, N., Kobayashi, M., Fukushima, A., Mori, M., Ichikawa, T., Matsui, K., Kuroda, H., Horii, Y., Tsumoto, Y., Sakakibara, H., Hirochika, H., Matsui, M., and Saito, K. (2010) Metabolomic screening applied to rice FOX Arabidopsis lines leads to the identification of a gene-changing nitrogen metabolism. Mol Plant 3: 125-142.

Ahringer, J. (2000) NuRD and SIN3: Histone deacetylase complexes in development. Trends Genet 16: 351-356.

Borghi, L., Bureau, M., and Simon, R. (2007) Arabidopsis JAGGED LATERAL ORGANS is expressed in boundaries and coordinates KNOX and PIN activity. Plant Cell 19: 1795-1808.

Bortiri, E., Chuck, G., Vollbrecht, E., Rocheford, T., Martienssen, R., and Hake, S. (2006) ramosa2 encodes a LATERAL ORGAN BOUNDARY domain protein that determines the fate of stem cells in branch meristems of maize. Plant Cell 18: 574-585.

Boudolf, V., Vlieghe, K., Beemster, G. T., Magyar, Z., Torres Acosta, J. A., Maes, S., Van Der Schueren, E., Inze, D., and De Veylder, L. (2004) The plant-specific cyclin-dependent kinase CDKB 1; 1 and transcription factor E2Fa-DPa control the balance of mitotically dividing and endoreduplicating cells in Arabidopsis. Plant Cell 16: 2683-2692.

Byrne, M. E., Barley, R., Curtis, M., Arroyo, J. M., Dunham, M., Hudson, A., and Martienssen, R. A. (2000) Asymmetric leaves 1 mediates leaf patterning and stem cell function in Arabidopsis. Nature 408: 967-971.

Chalfun-Junior, A., Franken, J., Mes, J. J., Marsch-Martinez, N., Pereira, A., and Angenent, G. C. (2005) ASYMMETRIC LEAVES2-LIKE1 gene, a member of the AS2/LOB family, controls proximal-distal patterning in Arabidopsis petals. Plant Mol Biol 57: 559-575.

Dangl, M., Brosch, G., Haas, H., Loidl, P., and Lusser, A. (2001) Comparative analysis of HD2 type histone deacetylases in higher plants. Planta 213: 280-285.

Evans, M. M. (2007) The indeterminate gametophyte1 gene of maize encodes a LOB domain protein required for embryo Sac and leaf development. Plant Cell 19: 46-62.

Garcia, D., Collier, S. A., Byrne, M. E., and Martienssen, R. A. (2006) Specification of leaf polarity in Arabidopsis via the trans-acting siRNA pathway. Curr Biol 16: 933-938.

Georgieva, E. I., López-Rodas, G., Sendra, R., Gröbner, P., and Loidl, P. (1991) Histone acetylation in Zea mays. II. Biological significance of post-translational histone acetylation during embryo germination. $J$ Biol Chem 266: 
18751-18760.

Graciet, E., Walter, F., Maoiléidigh, D. O., Pollmann, S., Meyerowitz, E. M., Varshavsky, A., and Wellmer, F. (2009) The N-end rule pathway controls multiple functions during Arabidopsis shoot and leaf development. Proc Natl Acad Sci USA 106, 13618-13623.

Guo, M., Thomas, J., Collins, G., and Timmermans, M. C. (2008) Direct repression of KNOX loci by the ASYMMETRIC LEAVES1 complex of Arabidopsis. Plant Cell 20: 48-58.

Ha C. M., Kim, G. T., Kim, B. C., Jun, J. H., Soh, M. S., Ueno, Y., Machida, Y., Tsukaya, H., and Nam, H. G. (2003) The BLADE-ON-PETIOLE 1 gene controls leaf pattern formation through the modulation of meristematic activity in Arabidopsis. Development 130: 161-172.

Horiguchi, G., Nakayama, H., Ishikawa, N., Kubo, M., Demura, T., Fukuda, H., and Tsukaya, H. (2010) ANGUSTIFOLIA3 Plays Roles in Adaxial/Abaxial Patterning and Growth in Leaf Morphogenesis. Plant Cell Physiol 2010 Nov 21. [Epub ahead of print]

Huang, W., Pi, L., Liang, W., Xu, B., Wang, H., Cai, R., and Huang, H. (2006) The proteolytic function of the Arabidopsis 26S proteasome is required for specifying leaf adaxial identity. Plant Cell 18: 2479-2492.

Husbands, A., Bell, E. M., Shuai, B., Smith, H. M., and Springer, P. S. (2007) LATERAL ORGAN BOUNDARIES defines a new family of DNA-binding transcription factors and can interact with specific bHLH proteins. Nucleic Acids Res 35: 6663-6671.

Ikezaki, M., Kojima, M., Sakakibara, H., Kojima, S., Ueno, Y., Machida, C., and Machida, Y. (2010) Genetic networks regulated by ASYMMETRIC LEAVES1 (AS1) and AS2 in leaf development in Arabidopsis thaliana: KNOX genes control five morphological events. Plant J 61: 70-82.

Inukai, Y., Sakamoto, T., Ueguchi-Tanaka, M., Shibata, Y., Gomi, K., Umemura, I., Hasegawa, Y., Ashikari, M., Kitano, H., and Matsuoka, M. (2005) Crown rootless1, which is essential for crown root formation in rice, is a target of an AUXIN RESPONSE FACTOR in auxin signaling. Plant Cell 17: 1387-1396.

Ishida, T., Adachi, S., Yoshimura, M., Shimizu, K., Umeda, M., and Sugimoto, K. (2010) Auxin modulates the transition from the mitotic cycle to the endocycle in Arabidopsis. Development 137: 63-71.

Iwakawa, H., Ueno, Y., Semiarti, E., Onouchi, H., Kojima, S., Tsukaya, H., Hasebe, M., Soma, T., Ikezaki, M., Machida, C., and Machida, Y. (2002) The ASYMMETRIC LEAVES2 gene of Arabidopsis thaliana, required for formation of a symmetric flat leaf lamina, encodes a member of a novel family of proteins characterized by cysteine repeats and a leucine zipper. Plant Cell Physiol 43: 467-78.

Iwakawa, H., Iwasaki, M., Kojima, S., Ueno, Y., Soma, T., Tanaka, H., Semiarti, E., Machida, Y., and Machida, C. (2007) Expression of the ASYMMETRIC LEAVES2 gene in the adaxial domain of Arabidopsis leaves represses cell proliferation in this domain and is critical for the development of properly expanded leaves. Plant J 51: 173-
184.

Jun, J. H., Ha, C. M., and Fletcher, J. C. (2010) BLADEON-PETIOLE1 coordinates organ determinacy and axial polarity in Arabidopsis by directly activating ASYMMETRIC LEAVES2. Plant Cell 22: 62-76.

Kasschau, K. D., Xie, Z., Allen, E., Llave, C., Chapman, E. J., Krizan, K. A., Carrington JC. (2003) P1/HC-Pro, a viral suppressor of RNA silencing, interferes with Arabidopsis development and miRNA function. Dev Cell 4: 205-217.

Koyama, T., Mitsuda, N., Seki, M., Shinozaki, K., and OhmeTakagi, M. (2010) TCP Transcription Factors Regulate the Activities of ASYMMETRIC LEAVES1 and miR164, as Well as the Auxin Response, during Differentiation of Leaves in Arabidopsis. Plant Cell 22: 3574-88.

Lawrence, R. J., Earley, K., Pontes, O., Silva, M., Chen, Z. J., Neves, N., Viegas, W., and Pikaard, C. S. (2004) A concerted DNA methylation/histone methylation switch regulates rRNA gene dosage control and nucleolar dominance. Mol Cell 13: 599-609.

Li, H., Xu, L., Wang, H., Yuan, Z., Cao, X., Yang, Z., Zhang, D., Xu, Y., and Huang, H. (2005) The Putative RNAdependent RNA polymerase RDR6 acts synergistically with ASYMMETRIC LEAVES 1 and 2 to repress BREVIPEDICELLUS and MicroRNA165/166 in Arabidopsis leaf development. Plant Cell 17: 2157-2171.

Lin, W. C., Shuai, B., and Springer, P. S. (2003) The Arabidopsis LATERAL ORGAN BOUNDARIESdomain gene ASYMMETRIC LEAVES2 functions in the repression of KNOX gene expression and in adaxialabaxial patterning. Plant Cell 15: 2241-2252.

Liu, H., Wang, S., Yu, X., Yu, J., He, X., Zhang, S., Shou, H., and $\mathrm{Wu}, \mathrm{P}$. (2005) ARL1, a LOB-domain protein required for adventitious root formation in rice. Plant J 43: 47-56.

Lusser, A., Brosch, G., Loidl, A., Haas, H., and Loidl, P. (1997) Identification of maize histone deacetylase HD2 as an acidic nucleolar phosphoprotein. Science 277: 88-91.

Mangeon, A., Bell, E. M., Lin, W. C., Jablonska, B., Springer, P. S. (2011) Misregulation of the LOB domain gene DDA1 suggests possible functions in auxin signalling and photomorphogenesis. J Exp Bot 62: 221-233.

Matsumura, Y., Iwakawa, H., Machida, Y., and Machida, C. (2009) Characterization of genes in the ASYMMETRIC LEAVES2/LATERAL ORGAN BOUNDARIES (AS2/ LOB) family in Arabidopsis thaliana, and functional and molecular comparisons between AS2 and other family members. Plant J 58: 525-537.

Moon, J., and Hake, S. (2010) How a leaf gets its shape. Curr Opin Plant Biol 14: 1-7.

Naito, T., Yamashino, T., Kiba, T., Koizumi, N., Kojima, M., Sakakibara, H., and Mizuno, T. (2007) A link between cytokinin and ASL9 (ASYMMETRIC LEAVES 2 LIKE 9) that belongs to the AS2/LOB (LATERAL ORGAN BOUNDARIES) family genes in Arabidopsis thaliana. Biosci Biotechnol Biochem 71: 1269-1278.

Nakazawa, M., Ichikawa, T., Ishikawa, A., Kobayashi, H., Tsuhara, Y., Kawashima, M., Suzuki, K., Muto, S., and Matsui, M. (2003) Activation tagging, a novel tool to 
dissect the functions of a gene family. Plant J 34: 741-750.

Nath, U., Crawford, B. C., Carpenter, R., and Coen, E. (2003) Genetic control of surface curvature. Science 299: 14041407.

Nurmberg, P. L., Knox, K. A., Yun, B. W., Morris, P. C., Shafiei, R., Hudson, A., and Loake, G. J. (2007) The developmental selector AS1 is an evolutionarily conserved regulator of the plant immune response. Proc Natl Acad Sci USA 104: 18795-18800.

Ogas, J., Kaufmann, S., Henderson, J., Somerville, C. (1999) PICKLE is a CHD3 chromatin-remodeling factor that regulates the transition from embryonic to vegetative development in Arabidopsis. Proc Natl Acad Sci USA 96: 13839-13844.

Oh, S. A., Park, K. S., Twell, D., Park, S. K. (2010) The SIDECAR POLLEN gene encodes a microspore-specific LOB/AS2 domain protein required for the correct timing and orientation of asymmetric cell division. Plant $J$ 64: 839-850.

Okushima, Y., Fukaki, H., Onoda, M., Theologis, A., and Tasaka, M. ARF7 and ARF19 regulate lateral root formation via direct activation of LBD/ASL genes in Arabidopsis. Plant Cell 19: 118-130.

Ori, N., Eshed, Y., Chuck, G., Bowman, J. L., Hake, S. (2000) Mechanisms that control knox gene expression in the Arabidopsis shoot. Development 127: 5523-5532.

Palatnik, J. F., Allen, E., Wu, X., Schommer, C., Schwab, R., Carrington, J. C., and Weigel, D. (2003) Control of leaf morphogenesis by microRNAs. Nature 425: 257-263.

Phelps-Durr, T. L., Thomas, J., Vahab, P., and Timmermans, M. C. (2005) Maize rough sheath2 and its Arabidopsis orthologue ASYMMETRIC LEAVES1 interact with HIRA, a predicted histone chaperone, to maintain knox gene silencing and determinacy during organogenesis. Plant Cell 17: 2886-2898.

Pinon, V., Etchells, J. P., Rossignol, P., Collier, S. A., Arroyo, J. M., Martienssen, R. A., and Byrne, M. E. (2008) Three PIGGYBACK genes that specifically influence leaf patterning encode ribosomal proteins. Development 135: 1315-1324.

Ramirez, J., Bolduc, N., Lisch, D., and Hake, S. (2009) Distal expression of knotted1 in maize leaves leads to reestablishment of proximal/distal patterning and leaf dissection. Plant Physiol 151: 1878-1888.

Rédei, G. P., and Hirono, Y. (1964) Linkage studies. Arabidopsis Inf Serv 1.9.

Rédei, G. P. (1965) Non-mendelian megagametogenesis in Arabidopsis. Genetics 51: 857-872.

Rubin, G., Tohge, T., Matsuda, F., Saito, K., Scheible, W. R. (2009) Members of the LBD family of transcription factors repress anthocyanin synthesis and affect additional nitrogen responses in Arabidopsis. Plant Cell 21: 3567-3584.

Sakamoto, T., Kamiya, N., Ueguchi-Tanaka, M., Iwahori, S., and Matsuoka, M. (2001) KNOX homeodomain protein directly suppresses the expression of a gibberellin biosynthetic gene in the tobacco shoot apical meristem. Genes Dev 15: 581-590.
Semiarti, E., Ueno, Y., Tsukaya, H., Iwakawa, H., Machida, C., and Machida, Y. (2001) The ASYMMETRIC LEAVES2 gene of Arabidopsis thaliana regulates formation of a symmetric lamina, establishment of venation and repression of meristem-related homeobox genes in leaves. Development 128: 1771-1783.

Serrano-Cartagena, J., Robles, P., Ponce, M. R., Micol, J. L. (1999) Genetic analysis of leaf form mutants from the Arabidopsis Information Service collection. Mol Gen Genet 261: 725-739.

Shuai, B., Reynaga-Peña, C. G., Springer, P. S. (2002) The lateral organ boundaries gene defines a novel, plant-specific gene family. Plant Physiol 129: 747-61.

Soyano, T., Thitamadee, S., Machida, Y., and Chua, N. H. (2008) ASYMMETRIC LEAVES2-LIKE19/LATERAL ORGAN BOUNDARIES DOMAIN30 and ASL20/LBD18 regulate tracheary element differentiation in Arabidopsis. Plant Cell 20: 3359-3373.

Tabata, R., Ikezaki, M., Fujibe, T., Aida, M., Tian, C. E., Ueno, Y., Yamamoto, K. T., Machida, Y., Nakamura, K., and Ishiguro, S. (2010) Arabidopsis auxin response factor6 and 8 regulate jasmonic acid biosynthesis and floral organ development via repression of class 1 KNOX genes. Plant Cell Physiol 51: 164-175.

Takahashi, H., Iwakawa, H., Nakao, S., Ojio, T., Morishita, R., Morikawa, S., Machida, Y., Machida, C., and Kobayashi, T. (2008) Knowledge-based fuzzy adaptive resonance theory and its application to the analysis of gene expression in plants. J Biosci Bioeng 106: 587-593.

Tamaoki, M., Sato, Y., Matsuoka, M.. (1997) Dorsoventral pattern formation of tobacco leaf involves spatial expression of a atobacco homeobox gene, NTH15. Genes Genet Syst 72: 1-8.

Taramino, G., Sauer, M., Stauffer, J. L. Jr, Multani, D., Niu, X., Sakai, H., and Hochholdinger, F. (2007) The maize (Zea mays L.) RTCS gene encodes a LOB domain protein that is a key regulator of embryonic seminal and post-embryonic shoot-borne root initiation. Plant J 50: 649-659.

Theodoris, G., Inada, N., and Freeling, M. (2003) Conservation and molecular dissection of ROUGH SHEATH2 and ASYMMETRIC LEAVES1 function in leaf development. Proc Natl Acad Sci USA 100: 6837-6842.

Timmermans, M. C., Hudson, A., Becraft, P. W, and Nelson, T. (1999) ROUGH SHEATH2: a Myb protein that represses knox homeobox genes in maize lateral organ primordia. Science 284: 151-153.

Tsiantis, M., Schneeberger, R., Golz, J. F., Freeling, M., Langdale, J. A. (1999) The maize rough sheath2 gene and leaf development programs in monocot and dicot plants. Science 284: 154-156.

Ueno, Y., Ishikawa, T., Watanabe, K., Terakuwa, S., Iwakawa, H., Okada, K., Machida, C., and Machida, Y. (2007) Histone deacetylases and ASYMMETRIC LEAVES2 are involved in the establishment of polarity in leaves of Arabidopsis. Plant Cell. 19: 445-457.

Waites, R., Selvadurai, H. R., Oliver, I. R., Hudson, A. (1998) The PHANTASTICA gene encodes a MYB transcription 
factor involved in growth and dorsoventrality of lateral organs in Antirrhinum. Cell 93: 779-789.

Wang, L., Gu, X., Xu, D., Wang, W., Wang, H., Zeng, M., Chang, Z., Huang, H., and Cui, X. (2011) miR396-targeted AtGRF transcription factors are required for coordination of cell division and differentiation during leaf development in Arabidopsis. J Exp Bot 62: 761-773.

Wu, K., Tian, L., Malik, K., Brown, D., Miki, B. (2000) Functional analysis of HD2 histone deacetylase homologues in Arabidopsis thaliana. Plant J 22: 19-27.

Xu, L., Xu, Y., Dong, A., Sun, Y., Pi, L., Xu, Y., and Huang, H. (2003) Novel as1 and as2 defects in leaf adaxialabaxial polarity reveal the requirement for ASYMMETRIC LEAVES1 and 2 and ERECTA functions in specifying leaf adaxial identity. Development 130: 4097-4107.

Xu, L., Yang, L., Pi, L., Liu, Q., Ling, Q., Wang, H., Poethig, R. S., and Huang, H. (2006) Genetic interaction between the AS1-AS2 and RDR6-SGS3-AGO7 pathways for leaf morphogenesis. Plant Cell Physiol 47: 853-863.

Yang, J. Y., Iwasaki, M., Machida, C., Machida, Y., Zhou, X., and Chua, N. H. (2008) betaC1, the pathogenicity factor of TYLCCNV, interacts with AS1 to alter leaf development and suppress selective jasmonic acid responses. Genes Dev 22: 2564-2577.

Yang, Y., Yu, X., and Wu, P. (2006) Comparison and evolution analysis of two rice subspecies LATERAL ORGAN BOUNDARIES domain gene family and their evolutionary characterization from Arabidopsis. Mol Phylogenet Evol 39: 248-262.

Yao, Y., Ling, Q., Wang, H., Huang, H. (2008) Ribosomal proteins promote leaf adaxial identity. Development 135: 1325-1334.

Yuan, Z., Luo, D., Li, G., Yao, X., Wang, H., Zeng, M., Huang, H., and Cui, X. (2010) Characterization of the AE7 gene in Arabidopsis suggests that normal cell proliferation is essential for leaf polarity establishment. Plant $J$ 64: 331342.

Zhou, C., Labbe, H., Sridha, S., Wang, L., Tian, L., LatoszekGreen, M., Yang, Z., Brown, D., Miki, B., and Wu, K. (2004) Expression and function of HD2-type histone deacetylases in Arabidopsis development. Plant J 38: 715-724. 